\title{
Hydrogen softening and optical transparency in Si-incorporated hydrogenated amorphous carbon films
}

Abbas, GA., Papakonstantinou, P., McLaughlin, JAD., Weijers-Dall, TDM., Elliman, RG., \& Filik, J. (2005).

Hydrogen softening and optical transparency in Si-incorporated hydrogenated amorphous carbon films. Journal of Applied Physics, 98(10), 103505. https://doi.org/10.1063/1.2132088

Link to publication record in Ulster University Research Portal

Published in:

Journal of Applied Physics

Publication Status:

Published (in print/issue): 01/11/2005

DOI:

10.1063/1.2132088

\section{Document Version}

Publisher's PDF, also known as Version of record

\section{General rights}

Copyright for the publications made accessible via Ulster University's Research Portal is retained by the author(s) and / or other copyright owners and it is a condition of accessing these publications that users recognise and abide by the legal requirements associated with these rights.

\section{Take down policy}

The Research Portal is Ulster University's institutional repository that provides access to Ulster's research outputs. Every effort has been made to ensure that content in the Research Portal does not infringe any person's rights, or applicable UK laws. If you discover content in the Research Portal that you believe breaches copyright or violates any law, please contact pure-support@ulster.ac.uk. 


\title{
Hydrogen softening and optical transparency in Si-incorporated hydrogenated amorphous carbon films
}

\author{
G. A. Abbas, ${ }^{\text {a) }}$ P. Papakonstantinou, and J. A. McLaughlin \\ Nanotechnology Research Institute, School of Electrical and Mechanical Engineering, University \\ of Ulster, Shore road, Newtownabbey BT37 OQB, Northern Ireland, United Kingdom
}

T. D. M. Weijers-Dall and R. G. Elliman

Department of Electronic Materials Engineering, Research School of Physical Sciences and Engineering, Australian National University, Canberra ACT 0200, Australia

\author{
J. Filik \\ School of Chemistry, University of Bristol, Cantock's Close, Bristol BS8 1TS, United Kingdom
}

(Received 19 January 2005; accepted 5 October 2005; published online 17 November 2005)

\begin{abstract}
High-resolution x-ray reflectivity (XRR) and heavy-ion elastic recoil detection were employed to study the role of hydrogen on the softening behavior observed in Si-incorporated hydrogenated amorphous carbon $(\mathrm{Si}-a-\mathrm{C}: \mathrm{H})$ films synthesized by plasma-enhanced chemical-vapor deposition using tetramethylsilane (TMS) precursor in $\mathrm{C}_{2} \mathrm{H}_{2}$ / Ar plasma. An enhancement of the optical band gap and a massive reduction in the density of the films prepared at high TMS flow rate were revealed, respectively, by spectroscopic ellipsometry and XRR analysis with the development of a double critical angle. A hydrogenation process was responsible for a rise in the density of voids and an associated reduction in the connectivity of the carbon network and the release of its residual stress. () 2005 American Institute of Physics. [DOI: 10.1063/1.2132088]
\end{abstract}

\section{INTRODUCTION}

Si-incorporated amorphous carbon films (either hydrogenated or hydrogen free) have great technological potential since they possess a unique combination of characteristics, including reduced internal stress, ${ }^{1}$ high deposition rate, ${ }^{2}$ high corrosion resistance, ${ }^{3}$ good adhesion to many substrates, ${ }^{4}$ improved thermal stability, ${ }^{5}$ low friction coefficients independent of relative humidity, ${ }^{6}$ and low wettability. ${ }^{7}$

The physical basis for these enhanced properties and the role of incorporated $\mathrm{Si}$ in diamond like carbon (DLC) ( $\mathrm{Si}-$ DLC) films have been extensively reported. ${ }^{8-11}$ However, the effect of silicon incorporation on the mechanical properties of DLC has not been firmly established and there is still a considerable controversy in the literature. ${ }^{6,12,13}$ Different studies have demonstrated different trends for the mechanical properties of $a-\mathrm{C}: \mathrm{H}$ films with $\mathrm{Si}$ addition. For example, De Martino et al. ${ }^{14}$ obtained hard Si-a-C:H films with hardness values (40 GPa) comparable to those of high $s p^{3}$ tetrahedral amorphous carbon $(t a-\mathrm{C})$ films. They attributed the excellent mechanical properties of their rf reactive sputtering films to the formation of an $s p^{3}$-coordinated and poorly hydrogenated $\mathrm{SiC}$ network. It was emphasized that the energy of the $\mathrm{Ar}$ ions played a significant role in the resultant microstructure by providing intermixing of carbon and silicon atoms and densification of the films by the removal of voids.

In contrast, Zhao et al. ${ }^{15}$ observed a progressive reduction trend in the nanomechanical properties of plasmaenhanced chemical-vapor deposition (PECVD) $a-\mathrm{C}: \mathrm{H}$ films as a result of $\mathrm{Si}$ addition. In this case it was suggested that the dramatic reduction in hardness and elastic modulus was

${ }^{a)}$ Electronic mail: g.abbas@ulster.ac.uk due to a hydrogenation process caused by the incorporation of hydrogen-rich tetramethylsilane (TMS) precursor gas into a mixture of $\mathrm{C}_{2} \mathrm{H}_{2} / \mathrm{Ar}$ plasma.

A different trend for the mechanical properties was also reported by Lee et al. ${ }^{16}$ for $\mathrm{Si}-a-\mathrm{C}: \mathrm{H}$ films deposited by plasma-assisted chemical-vapor deposition (PACVD) technique using a mixture of benzene and diluted silane. In this study, it was suggested that initial $\mathrm{Si}$ incorporation $(\leqslant 5$ at. \% $\mathrm{Si}$ ) increased the interlinking of the atomic bond network, which enhanced both the hardness and intrinsic stress. Further $\mathrm{Si}$ addition led to a saturation behavior, which was caused by the formation of a crystalline $\mathrm{SiC}$ phase and an increase in the number of $\mathrm{Si}-\mathrm{Si}$ and $\mathrm{Si}-\mathrm{H}$ bonds.

In this work we have conducted a thorough investigation of the interrelationship between the modified microstructure induced by TMS incorporation and the density, composition, residual stress, and optical and mechanical properties of the PECVD $a-\mathrm{C}: \mathrm{H}$ films. Such a study provides important insight onto the role of hydrogen and silicon addition, which is necessary for enhancing the performance of stress-free Si$a-\mathrm{C}: \mathrm{H}$ films as durable, antireflection, and protective coatings in optical applications.

\section{EXPERIMENTAL PROCEDURES}

$\mathrm{Si}-a-\mathrm{C}: \mathrm{H}$ films were deposited from a mixture of $\mathrm{C}_{2} \mathrm{H}_{2} / \mathrm{Ar}$ plasma and TMS precursor [total flow rate of 40 standard cubic centimeter per minute (SCCM)] onto $\mathrm{Si}$ (100) wafers using $13.56 \mathrm{MHz}$ PECVD reactor. All depositions were carried out at room temperature with a fixed dc self-bias voltage of $300 \mathrm{~V}$.

Heavy-ion elastic recoil detection (ERD) analysis was performed at the Australian National University using the 14 
TABLE I. The effect of silicon atomic concentrations on the binding energy $\left(E_{b}\right)$ and full width at half maximum (FWHM) of $\mathrm{C} 1 s, s p^{2}$, and $s p^{3}$ data are obtained from the peak fitting on $\mathrm{C} 1 s$ binding energy.

\begin{tabular}{|c|c|c|c|c|c|c|c|c|}
\hline \multicolumn{3}{|c|}{ Conc. (at. \%) } & \multicolumn{5}{|c|}{ Binding energy $(\mathrm{eV}) / \mathrm{FWHM}(\mathrm{eV})$ of $\mathrm{C} 1 \mathrm{~s}$} & \multirow{2}{*}{$\begin{array}{l}s p^{3} \\
\text { Ratio }\end{array}$} \\
\hline $\mathrm{C}$ & $\mathrm{Si}$ & $\mathrm{O}$ & $\mathrm{C}-\mathrm{Si}$ & $\mathrm{C}=\mathrm{C}$ & $\mathrm{C}-\mathrm{C}$ & $\mathrm{C}-\mathrm{O}$ & $\mathrm{O}-\mathrm{C}-\mathrm{O}$ & \\
\hline 85.19 & 1.47 & 13.34 & $283.8 / 1.3$ & $284.6 / 1.3$ & $285.4 / 1.4$ & $286.9 / 1.9$ & $289 / 1.8$ & 52.4 \\
\hline 82.58 & 3.13 & 14.29 & $283.3 / 1.3$ & $284.5 / 1.4$ & $285.2 / 1.5$ & $286.6 / 1.7$ & $288.3 / 2$ & 55.8 \\
\hline 78.07 & 6.19 & 15.74 & $283.6 / 1.2$ & $284.4 / 1.3$ & $285.1 / 1.5$ & $286.5 / 1.8$ & $288.3 / 2$ & 55.8 \\
\hline 72.09 & 8.64 & 19.27 & $283.7 / 1.4$ & $284.5 / 1.3$ & $285.3 / 1.5$ & $286.7 / 1.8$ & $288.5 / 2$ & 56.4 \\
\hline 71.85 & 10.16 & 17.99 & $283.4 / 1.5$ & $284.4 / 1.4$ & $285.1 / 1.6$ & $286.5 / 1.9$ & $288.5 / 2$ & 58.6 \\
\hline 67.61 & 14.83 & 17.56 & $283.8 / 1.5$ & $284.5 / 1.4$ & $285.2 / 1.6$ & $286.7 / 1.9$ & $288.5 / 2$ & 60.7 \\
\hline 62.5 & 15.49 & 22.01 & $282.9 / 1.7$ & $284.3 / 1.7$ & $285.1 / 1.8$ & $286.5 / 1.9$ & $288.0 / 2$ & 62.2 \\
\hline 65.8 & 16.25 & 17.95 & $283.8 / 1.5$ & $284.5 / 1.4$ & $285.2 / 1.6$ & $286.7 / 1.9$ & $288.5 / 2$ & 62.2 \\
\hline 62.93 & 18.95 & 18.12 & $283.8 / 1.4$ & $284.5 / 1.3$ & $285.3 / 1.6$ & $286.7 / 1.8$ & $288.5 / 2$ & 67.2 \\
\hline 59.67 & 21.54 & 18.8 & $283.8 / 1.4$ & $284.5 / 1.3$ & $285.2 / 1.6$ & $286.7 / 1.8$ & $288.5 / 2$ & 69.3 \\
\hline
\end{tabular}

UD heavy-ion accelerator facility. ${ }^{17}$ The $\mathrm{x}$-ray reflectivity (XRR) measurements were performed at the station 2.3 of Daresbury laboratory. Data in terms of density, layer thickness, and roughness were extracted by fitting the experimental curves to theoretical ones using Laptos software package.

An ISA Labram was used for the visible-range measurements, while a Renishaw 2000 spectrometer was employed for the UV range. X-ray photoelectron spectroscopy (XPS) analysis was carried out using KRATOS XSAM 800. The films' optical properties were measured by a Jobin Yvon ellipsometer over the range of $1.65-4.8 \mathrm{eV}$ at a fixed angle of $69.2^{\circ}$. A single Tauc-Lorentz oscillator model was used, ${ }^{18,19}$ for the analysis of the spectra, which is generally recognized as the best model for producing accurate values for amorphous carbon. ${ }^{20}$ Nanoindentation tests were performed with a MTS nanoindenter XP system. A surface profiler (Tencor $\mathrm{P}-10)$ was used to measure the residual stress by using the radius of curvature method.

\section{RESULTS AND DISCUSSION}

\section{A. XPS analysis}

The modification of bonding structure induced by TMS incorporation was monitored through evaluation of the overall $s p^{3} / s p^{2}$ hybridization ratio and the chemical arrangement between carbon and silicon (i.e., the fraction of $\mathrm{C}-\mathrm{Si}$ and $\mathrm{C}-\mathrm{C}$ bonds). The $\mathrm{C} 1 s$ XPS feature was fitted with five peaks representing five carbon bonding configurations. The composition, total $s p^{3}$ hybridization ratio, and bonding assignment of the $\mathrm{Si}-a-\mathrm{C}: \mathrm{H}$ films are presented in Table I. The bond assignments are consistent with other published works. ${ }^{21,22}$

Figure 1(a) illustrates the constituents bond ratios deduced from the deconvolution of C $1 s$ XPS spectra of the $\mathrm{Si}-a-\mathrm{C}: \mathrm{H}$ films as a function of $\mathrm{Si}$ concentration. As one can see, while the $\mathrm{C}-\mathrm{C}$ bonds are almost constant, the incorporated $\mathrm{Si}$ atoms substitute for $s p^{2}$-bonded carbon atoms causing a development of $\mathrm{C}-\mathrm{Si}$ bonds with the increase in the TMS $/ \mathrm{C}_{2} \mathrm{H}_{2}$ flow-rate ratio. Figure 1 (b) presents the total $s p^{3}$ hybridization ratio (i.e., the fraction of $\mathrm{C}-\mathrm{Si}$ and $\mathrm{C}-\mathrm{C}$ bonds) of $\mathrm{Si}-\mathrm{a}-\mathrm{C}: \mathrm{H}$ films as a function of $\mathrm{Si}$ concentration. The figure shows that carbon and silicon $s p^{3}$ sites are progressively developing with $\mathrm{Si}$ incorporation. As the TMS was introduced into the discharge plasma, the $\mathrm{Si}$ concentration increased. Since silicon forms only single bonds, Si atoms replace carbon in $s p^{2} \mathrm{C}$ bonds causing a promotion of the $s p^{3}$ hybridization bonding.

\section{B. Multiwavelength Raman spectroscopy}

It is well known that Raman scattering is a resonance process in which those configurations whose band gaps match the excitation energy are preferentially excited. Visibal (vis)-Raman spectroscopy is 50-230 times ${ }^{23,24}$ more sensitive to $s p^{2}$ sites than $s p^{3}$ because visible photons $(2.2 \mathrm{eV})$ preferentially excite the $\pi$ states. Therefore vis-Raman spectroscopy is able to probe only the $s p^{2}$ sites. It depends fundamentally on the ordering of $s p^{2}$ sites and only indirectly on the fraction of $s p^{3}$ sites. $^{25}$ In Fig. 2(a), the background of all Raman spectra is subtracted to illustrate clearly the changes in the spectra with $\mathrm{Si}$ addition. The figure clearly illustrates that $\mathrm{Si}-a-\mathrm{C}: \mathrm{H}$ samples exhibit spectra dominated by the socalled $G$ and $D$ peaks. Both features are related to the $\pi-\pi^{*}$ transitions at the $s p^{2}$ sites only. The $G$ peak is due to the bond stretching of all pairs of the $s p^{2}$ atoms in both rings and chains. The $D$ peak is due to the breathing modes of the $s p^{2}$ atoms in rings.

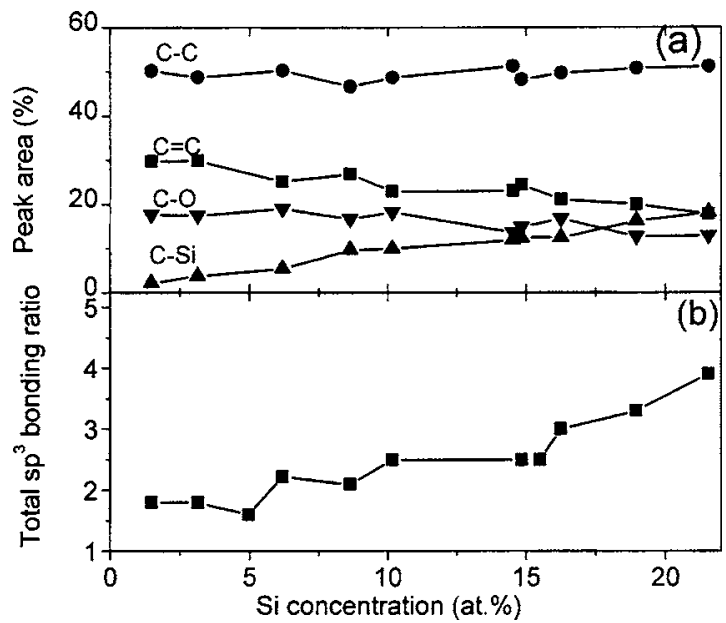

FIG. 1. (a) Deconvolution of C $1 s$ XPS core-level spectra and (b) total $s p^{3}$ bonding fraction ratio of $\mathrm{Si}-a-\mathrm{C}: \mathrm{H}$ films as a function of $\mathrm{Si}$ concentration. 

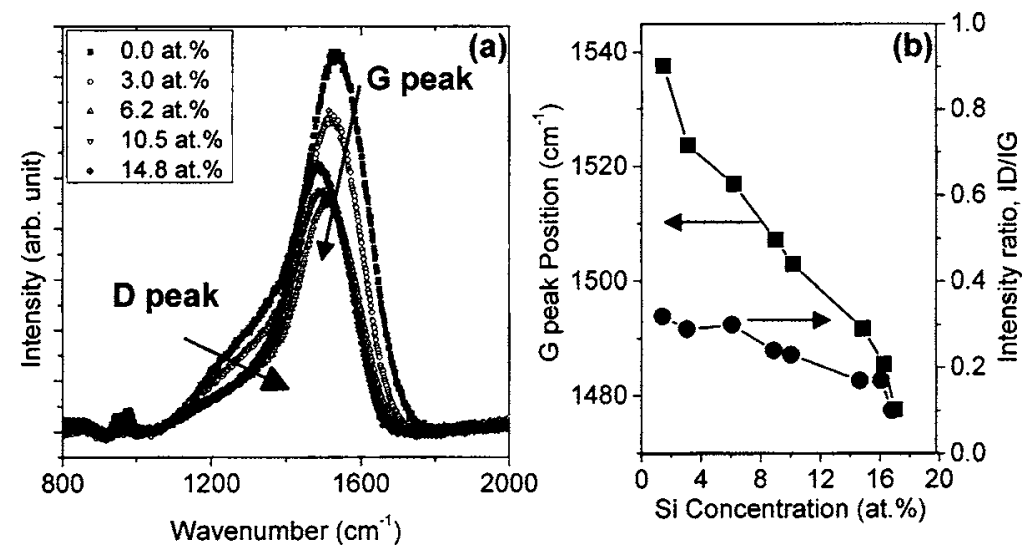

FIG. 2. (a) Normalized and background subtracted visible-Raman spectra and (b) fitting parameters [intensity ratio $\left(I_{D} / I_{G}\right)$ and $\mathrm{G}$ peak position] of $\mathrm{Si}-a-\mathrm{C}: \mathrm{H}$ films as a function of $\mathrm{Si}$ content.

The effect of silicon addition on Raman's parameters of the $a-\mathrm{C}: \mathrm{H}$ films is summarized in Fig. 2(b). The following important trends can be identified in the spectra: (i) the intensity ratio of $D$ and $G$ peaks, $I_{D} / I_{G}$, decreases, (ii) the $G$ peak position shifts to lower frequency; and (iii) the $G$ peak becomes more symmetric with a slight reduction of its width. It is well established that the $I_{D} / I_{G}$ ratio varies with the number and size of the $s p^{2}$ cluster domain size. Ferrari and Robertson $^{25,26}$ have proposed the following relation for estimating the size of ordered regions (i.e., clusters) from the $I_{D} / I_{G}$ ratio of carbon:

$$
\frac{I_{D}}{I_{G}}=C(\lambda) L_{a}^{2},
$$

where $C$ is a constant having a value of approximately 0.0055 at $514.5 \mathrm{~nm}$ and $L_{a}$ is the in-plane crystalline size in angstroms. This equation is valid only for crystalline size smaller than $20 \AA$. The cluster size as calculated using Eq. (1) decreased from 7.6 to $4.3 \AA$ as the silicon content increased from $0 \%$ to $16 \%$, respectively. This result indicates that the incorporation of $\mathrm{Si}$ atoms reduces the $s p^{2} \mathrm{C}$ cluster size by opening up the sixfold aromatic ring structure. This also points out that the position of the $G$ peak reflects the $s p^{2}$ cluster size in a way that the peak shifts to lower frequency with a decrease of the $s p^{2}$ cluster size. Our results are in agreement with that of the study of Yoshikawa et al. ${ }^{27}$ that was performed on pure $a-\mathrm{C}: \mathrm{H}$ films.

On the other hand, phonon confinement model has been used frequently to explain the variations in the Raman line shape of nanostructured materials, such as peak-frequency shifting, peak broadening, and emergence in peak symmetry. ${ }^{28}$ For disordered semiconductors, such as amorphous and nanocrystalline ones, the spatial confinement of phonons in a finite volume is expected to partially or fully relax the $q=0$ selection rule that determines the Raman spectra of the bulk crystals. The violation of the selection rule makes the optical phonons at $q \neq 0$ contribute to the Raman scattering (i.e., becomes Raman active). Therefore the phonon band broadens toward the low-energy side and shifts slightly to lower energies. ${ }^{29-31}$ As one can observe in Fig. 2(a), the $G$ peak becomes more symmetric with a slight reduction of its width. So, phonon confinement model could not give full explanation for our Raman results. Therefore, other factors should also participate in modifying the Raman spectra of our films including the release of the residual stress and the development of new chemical bonds. ${ }^{32}$ At low Si concentration, the silicon atoms predominantly substitute for the carbon atoms, as revealed by XPS earlier. As the atomic fraction of the silicon in the film increases, more and more silicon atoms substitute for the carbon atoms in the $s p^{2}$-bonded carbon clusters. Since silicon atom is heavier than the carbon atom, the vibration energy of the new structure becomes lower. ${ }^{33}$ Therefore incorporation of Si into the $a-\mathrm{C}: \mathrm{H}$ films will reduce the phonon vibration frequency causing a downshift of the $G$ peak.

The ascending slope of the vis-Raman spectra is obvious with the increase in hydrogen concentration (i.e., $\mathrm{H} / \mathrm{C}$ ratio) as illustrated in Fig. 3. Marchon et al. ${ }^{34}$ observed a similar behavior for magnetron-sputtered $a-\mathrm{C}: \mathrm{H}$ films containing 34 at. \% H. The development of Raman background slope with the increase in $\mathrm{H}$ concentration could be due to the saturation of nonradiative recombination sites (e.g., dangling bonds) by hydrogen addition. ${ }^{34}$ As TMS gas is introduced into the PECVD deposition chamber, a high fraction of hydrogen is incorporated into the $\mathrm{Si}-a-\mathrm{C}: \mathrm{H}$ films and terminated $\mathrm{CH}$ bonds are formed. This leads to an increase in the photoluminescence (PL) intensity of the vis-Raman spectra.

To monitor the development of the $s p^{3}$ hybridization bonds in the Si- $a-\mathrm{C}: \mathrm{H}$ films, we have employed UV-Raman spectroscopy (325 nm excitation wavelength), in which the $\sigma$ modes of $\mathrm{C}-\mathrm{C}$ bonds can be observed directly as a broad peak ( $T$ peak) located near $1100 \mathrm{~cm}^{-1} \cdot{ }^{35-37}$ The UV-Raman



FIG. 3. Raman background slope vs H/C ratio (determined using heavy-ion ERD analysis) of Si- $a-\mathrm{C}: \mathrm{H}$ samples. 


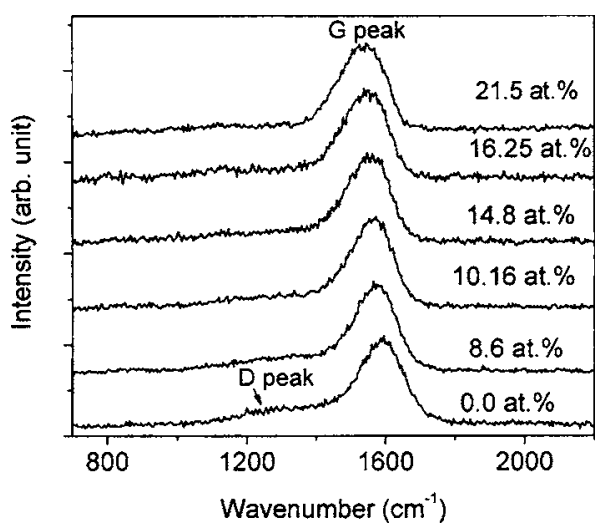

FIG. 4. UV Raman spectra of Si- $a$-C:H films with different silicon concentrations. The spectra are shifted to each other for ease of comparison.

spectra of the $\mathrm{Si}-a-\mathrm{C}: \mathrm{H}$ samples are presented in Fig. 4. As one can observe, despite the more symmetrical $G$ peak and the reduction in $D$ peak intensity, there is no indication of the development of a $T$ peak. This indicates that silicon inclusion in $a-\mathrm{C}: \mathrm{H}$ films does not promote the $s p^{3} \mathrm{C}-\mathrm{C}$ bonds. Instead, it converts the $s p^{2} \mathrm{C}$ to $s p^{3} \mathrm{C}-\mathrm{Si}$ (supported by XPS) or $s p^{3} \mathrm{C}-\mathrm{H}$ bonds.

\section{Ellipsometric spectroscopy analysis}

Figure 5(a) shows the optical-absorption coefficient $\alpha$ versus the photon energy for $\mathrm{Si}-a-\mathrm{C}: \mathrm{H}$ films with silicon contents of $0,6.2,10.2$, and 15.5 at. $\%$, respectively. By increasing the silicon concentration, the optical-absorption edge is shifted towards higher photon energy with a steeper slope. This trend indicates the development of films that possess a wider band gap. ${ }^{38}$ Figure 5(b1) confirms this suggestion as it clearly demonstrates that the optical band gap values, $E_{\text {opt }}$, rise with silicon. The optical data can be explained by a cluster model. ${ }^{39}$ In this model, Robertson suggested that there are two factors that control the optical band gap; those factors are (i) the gap distinguishes between $\pi$ and $\pi^{*}$ states on the $s p^{2}$ sites and (ii) the $s p^{2}$ cluster size. The increase of $\mathrm{Si}$ concentration in the $\mathrm{Si}-a-\mathrm{C}: \mathrm{H}$ films resulted in the decrease of the $s p^{2} \mathrm{C}$ cluster size. This has been confirmed by Raman data that are presented in Fig. 5(b2), which shows that the $I_{D} / I_{G}$ is decreasing with the development of $E_{\text {opt }}$.
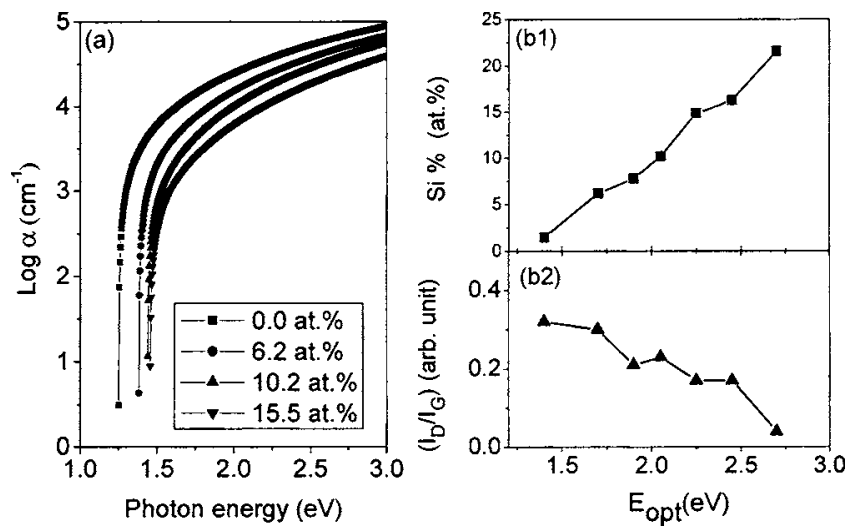

FIG. 5. (a) Optical-absorption edge vs photon energy as a function of $\mathrm{Si}$ content. (b1) The effect of Si incorporation on the optical band gap $\left(E_{\text {opt }}\right)$ and (b2) Raman $I_{D} / I_{G}$ ratio of a series of Si-a-C:H films.
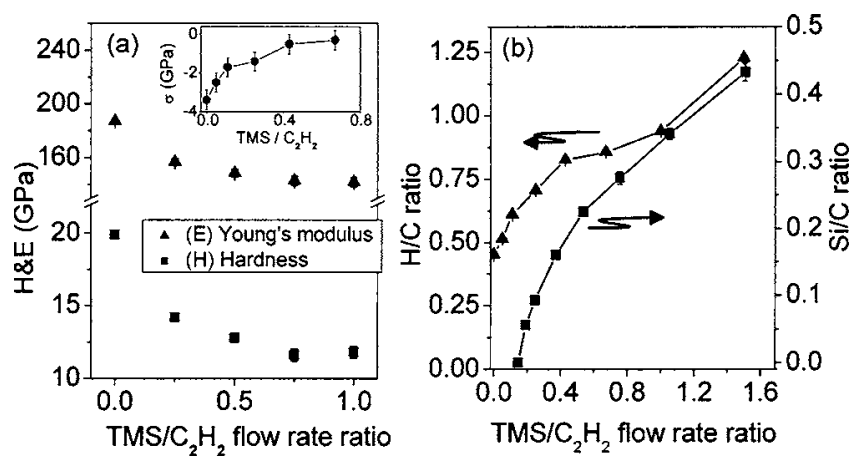

FIG. 6. The effect of Si incorporation on (a) Young's modulus $(E)$ and hardness $(H)$ of $a-\mathrm{C}: \mathrm{H}$ films. The inset illustrates the reduction of residual stress of the PECVD films as a result of the TMS-incorporation process. (b) The evolution of $\mathrm{H} / \mathrm{C}$ and $\mathrm{Si} / \mathrm{C}$ concentrations vs $\mathrm{TMS} / \mathrm{C}_{2} \mathrm{H}_{2}$ flow-rate ratio.

\section{Nanoindentation and heavy-ion ERD analysis}

Figure 6(a) demonstrates the dramatic reduction in the mechanical properties of the $\mathrm{Si}-a-\mathrm{C}: \mathrm{H}$ films as the TMS/ $\mathrm{C}_{2} \mathrm{H}_{2}$ ratio increases, while the inset illustrates the evolution of the residual stress in the films under $\mathrm{Si}$ incorporation. The deterioration in both Young's modulus $(E)$ and hardness $(H)$ could be accounted by the development of the $\mathrm{C}-\mathrm{Si}$ $s p^{3}$-hybridized bonds as revealed by XPS $(\mathrm{C}=\mathrm{C}$ bonds are progressively substituted by $\mathrm{C}-\mathrm{Si}$ bonds while $\mathrm{C}-\mathrm{C}$ bonds remain constant with $\mathrm{Si}$ addition). However, since the bond strength of $\mathrm{C}-\mathrm{Si}$ bond $(320 \mathrm{~kJ} / \mathrm{mole})$ is only $15 \%$ smaller than that of $s p^{2}$-hybridized $\mathrm{C}=\mathrm{C}$ bond $(380 \mathrm{~kJ} / \mathrm{mole}),{ }^{40}$ the formation of $\mathrm{C}-\mathrm{Si}$ bonds should not be considered as the major reason responsible for the progressive reduction in the mechanical strength and/or the residual stress in the $\mathrm{Si}-a-\mathrm{C}: \mathrm{H}$ films.

The reason for the reduction in nanomechanical properties is to be found on the effect of hydrogen content in the films. We employed heavy-ion ERD to obtain the relative change in the films composition (i.e., $\mathrm{H} / \mathrm{C}$ and $\mathrm{Si} / \mathrm{C}$ values) as a function of $\mathrm{TMS} / \mathrm{C}_{2} \mathrm{H}_{2}$ ratio and the results were plotted in Fig. 6(b). It is clear from the figure that the relative concentrations of both hydrogen and silicon are improved by the substitution of $\mathrm{C}$ atoms, as the TMS flow rate increased. The dissociation of hydrogen-rich precursor gas (i.e., TMS gas) by $\mathrm{C}_{2} \mathrm{H}_{2}$-enriched argon plasma is the main factor contributing to the increase of hydrogen concentration in the $\mathrm{Si}-a-\mathrm{C}: \mathrm{H}$ films. The inclusion of hydrogen, whose effect is to increase the density of voids, influences the connectivity and hardness of the network. ${ }^{41}$ This result is well documented in the literature. ${ }^{42}$ Additionally, high hydrogen concentration in the $\mathrm{Si}-a-\mathrm{C}: \mathrm{H}$ films enhances the formation of polymeric $s p^{3} \mathrm{CH}_{n}(n<1)$ structure, which dramatically affects the mechanical properties of our films.

\section{E. XRR analysis}

To verify the above suggestion that porosity was enhanced in our $\mathrm{Si}-a-\mathrm{C}: \mathrm{H}$ films by the inclusion of TMS precursor gas in the deposition plasma, we have employed highresolution XRR technique to measure the electron density of the films and to extract the porosity values. Figure 7 presents 


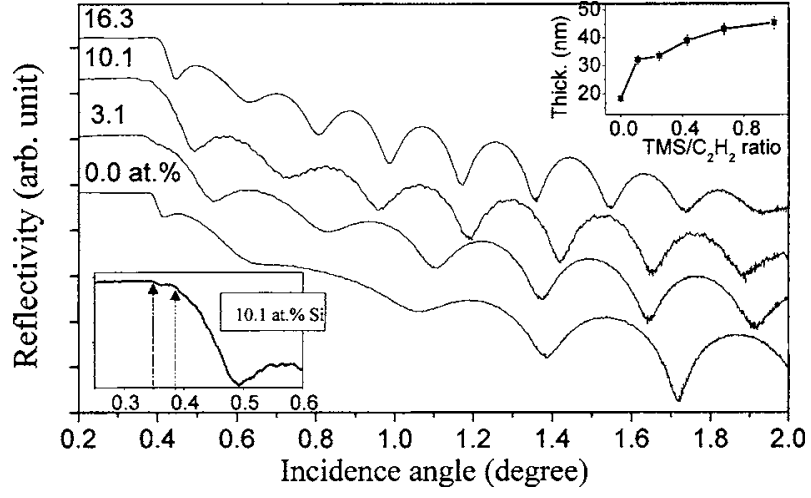

FIG. 7. X-ray reflectivity curves of $\mathrm{Si}-a-\mathrm{C}: \mathrm{H}$ samples with constant deposition time $(1 \mathrm{~min})$ as a function of $\mathrm{Si}$ concentration. The right inset illustrates the deposition rate as a function of $\mathrm{TMS} / \mathrm{C}_{2} \mathrm{H}_{2}$ ratio. The left inset shows a close-up figure illustrating the development of a double critical angle in the spectrum of the $\mathrm{Si}-a-\mathrm{C}: \mathrm{H}$ sample (10.1 at. \%) $\mathrm{Si}$ ).

typical XRR spectra of $\mathrm{Si}-a-\mathrm{C}: \mathrm{H}$ films, deposition time of $1 \mathrm{~min}$, as a function of $\mathrm{Si}$ concentration. The figure shows that at a specific value [i.e., critical angle $\left(\theta_{c}\right)$ ] a total external reflection occurs with an abrupt decrease in the reflectivity and a development of modulations (fringes) in the spectra. From $\theta_{c}$ one can obtain the electron density of overcoated material. The distance between fringes (period) is an indication of film's thickness. For more details about the XRR technique, readers are guided to Ref. 43. The right inset of Fig. 7 shows the increase of deposition rate with TMS addition, which is consistent with the increase in the number of fringes observed in the XRR curves. On the other hand, one can observe that except for the $a-\mathrm{C}: \mathrm{H}$ sample, all the Si-incorporated PECVD samples exhibited a double critical angle feature (as illustrated in the left inset of Fig. 7). This indicates that the overcoat possesses an electron density lower than the substrate material. ${ }^{43}$

The results from the XRR fitting are shown in Fig. 8(a). As the figure shows, the film density dramatically dropped from $2.3 \mathrm{~g} / \mathrm{cm}^{3}$ for film with zero $\mathrm{Si}$ to only a value of $1.1 \mathrm{~g} / \mathrm{cm}^{3}$ for film with 16.3 at. $\%$ silicon. In comparison with other work ${ }^{8}$ our films exhibit a significant density reduction. Different density trends are believed to be due to the dissimilarity in both the plasma chemistries and dynamics (i.e., type of precursor gases) of these different studies.

Assuming that the electron density of the matrix material contained in the porous film $\left(\rho_{e \text {,porous }}\right)$ is similar to that of the



FIG. 8. The effect of Si addition on (a) the electron-density values, and (b) the refractive index, measured at $633 \mathrm{~nm}$, of $a-\mathrm{C}: \mathrm{H}$ films. dense film $\left(\rho_{e \text {,nonporous }}\right)$ and the electron density is uniform throughout the thickness of the film, the porosity $P$ of a material is calculated as follows:

$$
P=1-\left(\rho_{e, \text { porous }} / \rho_{e, \text { nonporous }}\right) \text {. }
$$

From these measurements, the porosity of the $\mathrm{Si}-a-\mathrm{C}: \mathrm{H}$ film ( 16.3 at. $\% \mathrm{Si}$ ) is extracted to be $52 \%$. So, it is clear that porosity has been initiated and progressively developed with increasing the TMS flow rate. This has also been confirmed by spectroscopic ellipsometry data where the refractive index $(n)$ measured at wavelength of $633 \mathrm{~nm}$ exhibited a decreasing trend as illustrated in Fig. 8(b). This porosity trend is a very common feature in PECVD low dielectric constant $(K)$ materials, ${ }^{44}$ which are obtained using a precursor molecule with a ring-type structure, such as tetramethylcyclotetrasiloxane (TMCTS, $\left.\mathrm{Si}_{4} \mathrm{O}_{4} \mathrm{C}_{4} \mathrm{H}_{16}\right){ }^{44}$ Such a cyclic precursor structure could be preserved to some extent, under proper plasma conditions, to produce nanoporous films, with low dielectric constants.

\section{SUMMARY}

A series of PECVD Si- $a-\mathrm{C}: \mathrm{H}$ films (up to 21 at. $\% \mathrm{Si}$ ) was produced by using a gaseous mixture of $\mathrm{Ar} / \mathrm{C}_{2} \mathrm{H}_{2}$ plasma and TMS precursor gas. The $\mathrm{Si}-a-\mathrm{C}: \mathrm{H}$ films exhibited XRR spectra with a double critical angle as an indication for massive reduction in density value. Also, a significant reduction in the nanomechanical properties was observed. On the other hand, the ellipsometry results showed that while the refractive index slightly changed from 2.22 to 1.96 , the optical band gap significantly improved (from 1.35 to $2.7 \mathrm{eV}$ ) as a result of a developing higher $s p^{3}$-bonded structure (as revealed by XPS). The above-mentioned results, that seemed to be contradictory, were explained in terms of the increase of the density of voids (i.e., porosity) in the structure, which was associated with a hydrogenation process. The increasing trend of hydrogen content in the films was quantitatively confirmed by heavy-ion ERD and correlated with the development of an ascending slope in the visRaman spectra. The absence of a $T$ peak in the UV-Raman spectra $(325 \mathrm{~nm})$ confirmed that silicon incorporation in the $a-\mathrm{C}: \mathrm{H}$ samples did not promote the formation of $s p^{3} \mathrm{C}-\mathrm{C}$ bonds but converted the $s p^{2} \mathrm{C}$ to $s p^{3} \mathrm{C}-\mathrm{Si}$ (supported by $\mathrm{XPS}$ ). Therefore, $s p^{3}$ hybridization process in the films was developed but with more polymerlike and porous structure.

\section{ACKNOWLEDGMENTS}

The XRR measurements were performed at CCRLC facility at Daresbury (station 2.3). Special thanks to Steve Thomas for the guidance with $\mathrm{x}$-ray measurements.

${ }^{1}$ G. A. Abbas, J. McLaughlin, and E. Harkin-Jones, Diamond Relat. Mater. 13, 1342 (2004)

${ }^{2}$ L. Jiang, X. Chen, X. Wang, L. Xu, F. Stubhan, and K.-H. Merkel, Thin Solid Films 352, 97 (1999).

${ }^{3}$ P. Papakonstantinou, J. F. Zhao, P. Lemoine, E. T. McAdams, and J. A. McLaughlin, Diamond Relat. Mater. 11, 1074 (2002).

${ }^{4}$ J. Michler, M. Tobler, and E. Blank, Diamond Relat. Mater. 8, 510 (1999).

${ }^{5}$ W.-J. Wu and M.-H. Hon, Surf. Coat. Technol. 111, 134 (1999).

${ }^{6}$ K. Oguri and T. Arai, J. Mater. Res. 5, 2567 (1990). 
${ }^{7}$ M. Gischke, A. Hieke, F. Morgenweck, and H. Dimigen, Diamond Relat. Mater. 7, 454 (1998).

${ }^{8}$ B. Racine, A. C. Ferrari, N. A. Morrison, I. Hutchings, W. I. Milne, and J. Robertson, J. Appl. Phys. 90, 5002 (2001).

${ }^{9}$ J. F. Zhao, P. Lemoine, Z. H. Liu, J. P. Quinn, P. Maguire, and J. A. McLaughlin, Diamond Relat. Mater. 10, 1070 (2001).

${ }^{10}$ M. Ban and T. Hasegawa, Surf. Coat. Technol. 162, 1 (2002).

${ }^{11}$ S. S. Camargo, A. L. Baia Neto, R. A. Santos, F. L. Freire, Jr., R. Carius, and F. Finger, Diamond Relat. Mater. 7, 1155 (1998).

${ }^{12}$ J. Meneve, R. Jacobs, F. Lostak, L. Eersels, E. Dekempeneer, and J. Smeets, Mater. Res. Soc. Symp. Proc. 308, 671 (1993).

${ }^{13}$ S. Miyake, T. Miyamoto, and R. Kaneko, Wear 168, 155 (1993).

${ }^{14}$ C. De Martino, G. Fusco, G. Mina, A. Tagliaferro, L. Vanzetti, L. Calliari, and M. Anderle, Diamond Relat. Mater. 6, 559 (1997).

${ }^{15}$ J. F. Zhao, P. Lemoine, Z. H. Liu, J. P. Quinn, P. Maguire, and J. A. McLaughlin, Diamond Relat. Mater. 10, 1070 (2001).

${ }^{16}$ K.-R. Lee, M.-G. Kim, S.-J. Cho, K. Y. Eun, and T.-Y. Seong, Thin Solid Films 308-309, 263 (1997).

${ }^{17}$ R. G. Elliman, H. Timmers, T. R. Ophel, T. D. M. Weijers, L. S. Wielunski, and G. L. Harding, Nucl. Instrum. Methods Phys. Res. B 161-163, 231 (2000)

${ }^{18}$ G. E. Jellison and F. A. Modine, Appl. Phys. Lett. 69, 371 (1996).

${ }^{19}$ G. E. Jellison and F. A. Modine, Appl. Phys. Lett. 69, 2137 (1996).

${ }^{20}$ A. Canillas, M. C. Polo, J. L. Andula, J. Sancho, S. Bosch, J. Robertson, and W. I. Milne, Diamond Relat. Mater. 10, 1132 (2001).

${ }^{21}$ P. Patsalas, M. Handrea, S. Logothetidis, M. Gioti, S. Kennou, and W. Kautek, Diamond Relat. Mater. 10, 960 (2001).

${ }^{22}$ L. Li, H. Zhang, Y. Zhang, P. K. Chu, X. Tian, L. Xia, and X. Ma, Mater. Sci. Eng., B 94, 95 (2002).

${ }^{23}$ N. Wada, P. J. Gaczi, and A. Solin, J. Non-Cryst. Solids 35-36, 543 (1980).

${ }^{24}$ S. R. Salis, D. J. Gardiner, M. Bowden, J. Savage, and D. Rod-way, Diamond Relat. Mater. 5, 589 (1996).

${ }^{25}$ A. C. Ferrari and J. Robertson, Phys. Rev. B 61, 14095 (2000).
${ }^{26}$ C. Ferrari and J. Robertson, Phys. Rev. B 63, 121405 (2001).

${ }^{27}$ M. Yoshikawa, N. Nagai, M. Matsuki, H. Fukuda, G. Katagiri, H. Ishida, A. Ishitani, and I. Nagai, Phys. Rev. B 46, 7169 (1992).

${ }^{28}$ R. J. Nemanich, S. A. Solin, and R. M. Martin, Phys. Rev. B 23, 6348 (1981).

${ }^{29}$ H. Richter, Z. P. Wang, and L. Ley, Solid State Commun. 39, 625 (1981).

${ }^{30}$ I. H. Campbell and P. M. Fauchet, Solid State Commun. 58, 739 (1986).

${ }^{31}$ J. D. Moreno, F. Aullo-Rueda, E. Montoya, M. L. Marcos, J. GonzalezVelasco, R. Guerrero-Lemus, and J. M. Martinez-Duart, Appl. Phys. Lett. 71, 2166 (1997)

${ }^{32}$ J. R. Shi, X. Shi, Z. Sun, E. Liu, L. K. Cheah, and X. Z. Jin, J. Phys.: Condens. Matter 11, 5111 (1999).

${ }^{33}$ D. J. Li, F. Z. Cui, and H. Q. Gu, Appl. Surf. Sci. 137, 30 (1999).

${ }^{34}$ B. Marchon, J. Gui, K. Grannen, G. C. Rauch, J. W. Ager, S. R. P. Silva, and J. Robertson, IEEE Trans. Magn. 33, 3148 (1997).

${ }^{35}$ K. W. R. Gilkes, H. S. Sands, D. N. Batchelder, J. Robertson, and W. I. Milne, Appl. Phys. Lett. 70, 1980 (1997).

${ }^{36}$ K. W. R. Gilkes, S. Prawer, K. W. Nugent, J. Robertson, H. S. Sands, Y. Lifshitz, and X. Shi, J. Appl. Phys. 87, 7283 (2000).

${ }^{37}$ V. I. Merkulov, J. S. Lannin, C. H. Munro, S. A. Asher, V. S. Veerasamy, and W. I. Milne, Phys. Rev. Lett. 78, 4869 (1997).

${ }^{38}$ L. K. Cheah, X. Shi, B. K. Tay, and E. Liu, Surf. Coat. Technol. 105, 91 (1998).

${ }^{39}$ J. Robertson, Philos. Mag. Lett. 57, 143 (1988).

${ }^{40}$ A. Chehaidar, R. Carles, A. Zwick, C. Meunier, B. Cros, and J. Durand, J. Non-Cryst. Solids 169, 37 (1994).

${ }^{41}$ J. Hong, A. Goullet, and G. Turban, Thin Solid Films 352, 41 (1999).

${ }^{42}$ A. L. Baia Neto, R. A. Santos, F. L. Freire, Jr., S. S. Camargo, Jr., R. Carius, F. Finger, and W. Beyer, Thin Solid Films 293, 206 (1997).

${ }^{43}$ A. C. Ferrari et al., Phys. Rev. B 62, 11089 (2000).

${ }^{44}$ A. Grill, L. Perraud, V. Patel, C. Jahnes, and S. Cohen, Mater. Res. Soc. Symp. Proc. 565, 107 (1999); A. Grill, C. Jahnes, V. Patel, and L. Perraud, U.S. Patent, No. 6,147,009 (2000). 